Uijtdewilligen, L., Twisk, J.W.R., Chinapaw, M.J.M., Koppes, L.L.J., Mechelen, W. van, Singh, A.S. Longitudinal person-related determinants of physical activity in young adults. Medicine and Science in Sports and Exercise: 2014, 46(3), 529-536

\begin{tabular}{|c|c|}
\hline $\begin{array}{l}\text { Postprint } \\
\text { Version }\end{array}$ & 1.0 \\
\hline Journal website & $\begin{array}{l}\text { http://journals.Iww.com/acsm- } \\
\text { msse/pages/articleviewer.aspx?year=2014\&issue }=03000 \& \text { article }=00013 \& \text { type }= \\
\text { abstract }\end{array}$ \\
\hline Pubmed link & http://www.ncbi.nlm.nih.gov/pubmed/24042310 \\
\hline DOI & 10.1249/MSS.0000000000000126 \\
\hline
\end{tabular}

\title{
Longitudinal Person-Related Determinants of Physical Activity in Young Adults
}

\author{
UIJTDEWILLIGEN, LÉONIE ${ }^{1}$; TWISK, JOS W. R. ${ }^{2,3}$; CHINAPAW, MAI J. M. ${ }^{1,4}$; \\ KOPPES, LANDO L. J. ${ }^{5}$; VAN MECHELEN, WILLEM ${ }^{1,4}$; SINGH, AMIKA S. ${ }^{1}$ \\ ${ }^{1}$ Department of Public and Occupational Health, EMGO ${ }^{+}$Institute for Health and Care \\ Research, VU University Medical Center, Amsterdam, THE NETHERLANDS; \\ ${ }^{2}$ Department of Health Sciences, Section Methodology and Applied Biostatistics, VU \\ University Medical Center, Amsterdam, THE NETHERLANDS; \\ ${ }^{3}$ Department of Epidemiology and Biostatistics, VU University Medical Center, Amsterdam, \\ THE NETHERLANDS; \\ ${ }^{4}$ Body@Work, Research Center Physical Activity, Work and Health, TNO-VU University \\ Medical Center, Amsterdam, THE NETHERLANDS; and \\ ${ }^{5}$ Division Work and Employment, TNO, Hoofddorp, THE NETHERLANDS \\ Address for correspondence: Willem van Mechelen, M.D., Ph.D., FACSM., Department of \\ Public and Occupational Health, EMGO ${ }^{+}$Institute for Health and Care Research, VU \\ University Medical Center, van der Boechorststraat 71081 BT, Amsterdam, The \\ Netherlands; E-mail: w.vanmechelen@vumc.nl.
}

\begin{abstract}
Purpose: This study aimed to examine the longitudinal associations of personrelated factors with physical activity (PA) behavior in young adults.

Methods: We analyzed longitudinal self-reported time spent in moderateintensity PA (MPA; 4-7 METs) and vigorous-intensity PA (VPA; >7 METs) from 499 young adults (49\% male) who participated in the Amsterdam Growth and Health Longitudinal Study at the age of 21, 27, 32, and $36 \mathrm{yr}$. Sociodemographic factors (i.e., marital and employment status), physical factors (i.e., skinfolds, aerobic fitness, neuromotor fitness, back problems, and general health status), psychological factors (i.e., problem and emotion focused coping, mild health complaints, and personality), and behavioral factors (i.e., alcohol consumption, smoking, and energy intake) were assessed at each time point. We performed sex-specific univariable and multivariable generalized estimating equations.

Results: Men and women with higher aerobic fitness were more moderately and vigorously active. Not having paid work was associated with more MPA in both men and women. Men with part-time paid work, lower scores on dominance, higher scores on hostility, and above moderate alcohol consumption (i.e., >=140
\end{abstract}


Uijtdewilligen, L., Twisk, J.W.R., Chinapaw, M.J.M., Koppes, L.L.J., Mechelen, W. van, Singh, A.S. Longitudinal person-related determinants of physical activity in young adults. Medicine and Science in Sports and Exercise: 2014, 46(3), 529-536

g of alcohol per week) were more moderately active. Divorced women and those with better physical flexibility spent more time in MPA. Men having fulltime paid work, with a good general health status and nonsmokers, were more vigorously active. Women being married/living together, who had better physical flexibility, lower scores on inadequacy, higher scores on dominance, and low caloric intake (around $2000 \mathrm{kcal} \cdot \mathrm{d}^{-1}$ ) were more vigorously active.

Conclusion: Several sociodemographic, physical, psychological, and behavioral factors were associated with PA in Dutch young adults. Determinants were different for MPA and VPA and for men and women.

Despite the clear evidence of the physical and mental health benefits of regular participation in physical activity (PA) (43), the worldwide prevalence of physical inactivity is still high (16).

Considered as the fourth leading global risk factor for mortality due to noncommunicable chronic diseases (57), physical inactivity is posing a serious threat to public health. As such, numerous interventions have been developed aimed at increasing PA levels across the life span $(5,29)$. Since sustained behavioral change is difficult (5), primary prevention of physical inactivity might be more successful, especially when focusing on specific groups that are at increased risk of having an inactive lifestyle. Therefore, knowledge of key determinants of PA is essential for the identification of risk groups as well as for the development of effective interventions (8).

Nonetheless, a recent "review of reviews" by Bauman et al. (8) that summarized the evidence on correlates of PA in adults, concluded that only few consistent factors affecting PA behavior have been identified. One important issue within this field of research is that most studies examining factors that potentially influence adults' PA behavior have a cross-sectional design. Studies applying a longitudinal observational design could identify factors that have strong associations with PA (9). Therefore, more prospective studies are required to examine these relationships. There is also a lack of studies investigating 1) the determinants of PA in different contexts, 2) the PA patterns at various life stages, and 3) the determinants of moderate-intensity PA (MPA) (49).

In the Amsterdam Growth and Health Longitudinal Study (AGAHLS) PAincluding a large range of activities in various settings and of different intensitieswas measured prospectively from adolescence into adulthood along with information on sociodemographic, physical, psychological, and behavioral factors. In the light of the research gaps addressed previously, the objective of the present study was to examine the longitudinal associations of these factors with MPA and vigorousintensity PA (VPA) in young adults who participated in the AGAHLS and were followed up from age 21 to 36 yr. In 2011, an estimated 43\% of Dutch young adults (age 18-34 yr) did not comply with the Dutch Public Health Physical Activity Guideline (i.e., to accumulate at least 30 min of moderate to vigorous intensity PA per day) and around 74\% did not comply with the Strenuous Intensity Physical Activity Guideline (i.e., to accumulate at least $20 \mathrm{~min}$ of VPA for at least 3 times a week [25]). Identifying determinants of PA in this particular population is thus highly relevant. 
Uijtdewilligen, L., Twisk, J.W.R., Chinapaw, M.J.M., Koppes, L.L.J., Mechelen, W. van, Singh, A.S. Longitudinal person-related determinants of physical activity in young adults. Medicine and Science in Sports and Exercise: 2014, 46(3), 529-536

\section{METHODS}

\section{Participants and procedures.}

The present study is part of the AGAHLS. This observational cohort started in the school year 1976/1977 to measure the natural course of growth, health, and lifestyle of almost 600 thirteen-year-old Dutch secondary school pupils. A detailed description of the study rationale, recruitment procedures and protocol, and information on study attrition has been reported previously $(45,50)$. At the time of the fifth follow-up measurement in 1985, AGAHLS participants had reached adult age. From this measurement on, comprehensive sociodemographic information (e.g., marital and employment status) was assessed. Therefore, the present analyses are based on data from men and women who took part in the fifth (1985), sixth (1991), eighth (1996/1997), and/or ninth (2000) follow-up measurement of the AGAHLS. Participants were then age 21, 27, 32, and 36 yr on average, respectively. The seventh follow-up measurement (1993) was excluded because of limited measured data on several physical and psychological variables. From 1985 to 2000, data on at least one of the sociodemographic, physical, psychological, or behavioral variables were available for 515 participants (48\% male). Of those, 16 provided no data on PA and were therefore not fitting the inclusion criteria of the present study. Participants with data on PA and sociodemographic, physical, psychological, or behavioral variables in at least one point in time were included, resulting in a sample of 499 participants (49\% male). The AGAHLS was approved by the medical ethics committee of the VU University Medical Center, Amsterdam, the Netherlands. All subjects provided their written informed consent.

\section{Physical activity.}

Habitual PA was assessed in a semistructured face-to-face interview (developed for the AGAHLS [53]), covering PA over the previous 3 months. In this interview, information was assessed on participation in (un)organized sports activities, active transportation to and from school/work, physical exertion at school/work, stair climbing, and other leisure-time activities. Activities with a duration of less than 5 min and an intensity less than four times the basal metabolic rate ( $<4$ METs) were not taken into account. All other activities were classified as light ( $4<7$ METs), moderate ( $7<10$ METs), or vigorous ( $>=10$ METs) intensity, based on literature dating from the 1960s and 1970s (32). To ensure a consistent PA measure in the AGAHLS, this procedure was continued even when the classification of PA intensity into MET value categories evolved over the years (1-3). To resemble MET values reported in recent research, we classified $4<7$ METs activities as MPA and $>=7$ METs activities as VPA. For both categories, the average weekly time spent on those different intensity activities was calculated and used as outcome in the current analyses (see Table, Supplementary Digital Content 1, http://links.lww.com/MSS/A290, Details of the PA measure used in the Amsterdam Growth and Health Longitudinal Study [AGAHLS]).

\section{Assessment of person-related determinants.}

The current study considered sociodemographic, physical, psychological, and behavioral factors as potential determinants of PA. Sociodemographic factors included self-reported marital and employment status. Physical factors included (a) sum of skinfolds measured by a Harpenden skinfold caliper, (b) aerobic fitness $\left(\mathrm{V} \cdot \mathrm{O}_{2 \max }\right)$ assessed by a maximal running test performed on a treadmill, and (c) 
Uijtdewilligen, L., Twisk, J.W.R., Chinapaw, M.J.M., Koppes, L.L.J., Mechelen, W. van, Singh, A.S. Longitudinal person-related determinants of physical activity in young adults. Medicine and Science in Sports and Exercise: 2014, 46(3), 529-536

neuromotor fitness assessed by the MOPER Fitness Test consisting of four strength tests, two coordination/speed tests, and one flexibility test (32). In addition, selfreported back problems and general health status were regarded as physical factors (32). Psychological factors included (a) coping style (Ways of Coping Checklist [54]), (b) mild health complaints (Checklist on Experienced Health [28]), and (c) personality (Dutch Personality Inventory [38]). Behavioral factors included selfreported alcohol consumption $(33,44)$, smoking, and energy intake (44) (see Table, Supplementary Digital Content 2, http://links.lww.com/MSS/A291, Details on the assessment of potential person-related determinants of PA in the Amsterdam Growth and Health Longitudinal Study [AGAHLS]). All variables were assessed at each of the four follow-up measurements.

\section{[TABLE 1] [TABLE 2]}

\section{Statistical analysis.}

For each follow-up measurement descriptive statistics were calculated for all potential determinants and for MPA and VPA. Furthermore, normality of the PA data was checked by plotting histograms. We found that both MPA and VPA data were positively skewed. Therefore, both were log transformed before performing the main data analyses. Applying log transformation, we successfully normalized the PA data. In longitudinal studies, the same participants are measured repeatedly over time. As such, repeated observations from each subject are dependent of each other and estimation of the parameters of the statistical model should take into account this within-subject correlation. Generalized estimating equations (GEE) is a statistical technique that adjusts for this within-subject correlation, making the technique wellsuited for longitudinal data analyses. Thus, we performed age-adjusted univariable linear GEE analyses with an exchangeable correlation structure to examine the associations between each potential determinant and MPA and VPA. An interaction term between each potential determinant and sex was added to every univariable GEE to check for effect modification. For both PA categories, multivariable linear GEE including all independent variables was then used to explore the most important determinants. Independent variables with the highest $\mathrm{P}$ values were removed one by one from the model, until only variables with $\mathrm{P}<0.05$ remained. All parameter estimates were expressed with a 95\% confidence interval (95\% confidence interval), and results were considered significant if $\mathrm{P}<0.05$. Analyses were conducted with the Statistical Package for the Social Sciences for Windows (version 18.0; SPSS Inc., Chicago, IL).

\section{RESULTS}

Table 1 presents the median and interquartile range $\left(\mathrm{min} \cdot \mathrm{wk}^{-1}\right)$ that AGAHLS participants spent in MPA and VPA for the 15-yr period of follow-up. Table 2 shows descriptive information of the study sample at different time points. At each time point, women were slightly overrepresented. By the year 2000, most participants (78\%) were either married or living together. The percentage of participants without paid work decreased from 39\% in 1985 to 7\% in 2000 (data not shown). The percentage of part-time working women steadily increased over the years (from 18\% to $70 \%$ ), whereas by the year 2000, the vast majority of men (87\%) had a full-time job. Because some of the univariable associations between potential 
Uijtdewilligen, L., Twisk, J.W.R., Chinapaw, M.J.M., Koppes, L.L.J., Mechelen, W. van, Singh, A.S. Longitudinal person-related determinants of physical activity in young adults. Medicine and Science in Sports and Exercise: 2014, 46(3), 529-536

determinants and PA categories were different for men and women (i.e., showed a significant interaction with sex; data not shown), we decided to perform univariable and multivariable GEE analyses for men and women separately (see Table, Supplementary Digital Content 3, http://links.lww.com/MSS/A292, Results of univariable GEE analyses presenting associations between person-related characteristics and physical activity for men; and Table, Supplementary Digital Content 4, http://links.lww.com/MSS/A293, Results of univariable GEE analyses presenting associations between person-related characteristics and physical activity for women). Tables 3 and 4 present sex-specific multivariable associations between potential determinants and MPA and VPA, respectively.

\section{Moderate-intensity PA.}

Men and women having no paid work spent significantly more time in MPA than those working full time (this was also the case for part-time working men). Higher aerobic fitness was significantly associated with more time spent in MPA in both men and women. Men who consumed more than 140 grams of alcohol per week were significantly more moderately active than their nondrinking peers. Also in men, a lower score on dominance and a higher score on hostility were significantly associated with more time spent in MPA.

Furthermore, divorced women (compared with those being married/living together) and women with a better physical flexibility were significantly more moderately active.

\section{Vigorous-intensity PA.}

Full-time working men spent significantly more time in VPA than those without paid work. For women, no association of employment status with VPA was found for the 15-yr of follow-up. Higher aerobic fitness was significantly associated with more time spent in VPA in both men and women. In addition, a better physical flexibility in women and a good self-reported general health status in men were significantly associated with higher levels of VPA. Nonsmoking men spent significantly more time in VPA compared with smokers.

Besides that, it was found that women being married/living together spent significantly more time in VPA than divorced women. Also, women with a lower score on inadequacy, a higher score on dominance and those in the lowest tertile of energy intake (i.e., consuming up to around $2000 \mathrm{kcal} \cdot \mathrm{d}^{-1}$ ) spent significantly more time in VPA.

\section{[TABLE 3] [TABLE 4]}

\section{DISCUSSION}

Although PA is widely recognized as an important component of a healthy lifestyle (37), young adults in the Netherlands and beyond are not participating in sufficient MPA and VPA $(22,25)$. For better understanding of the key determinants of PA in a young Dutch adult population, we conducted the current study, which assessed sociodemographic, physical, psychological, and behavioral factors prospectively associated with MPA and VPA. We analyzed sex-specific multivariable models and examined which factors were most important for PA. Information on factors that affect MPA and VPA is essential for the identification of risk groups (targeted prevention) as well as for the development of effective interventions. However, to 
Uijtdewilligen, L., Twisk, J.W.R., Chinapaw, M.J.M., Koppes, L.L.J., Mechelen, W. van, Singh, A.S. Longitudinal person-related determinants of physical activity in young adults. Medicine and Science in Sports and Exercise: 2014, 46(3), 529-536

date, only few consistent factors influencing PA behavior have been identified (8), which may partly explain the lack of interventions that effectively change PA behavior on the long term $(10,13,27,42)$. With this prospective study, we aim to contribute to the study of determinants in young adults and, as such, improve future intervention development.

\section{Marital and employment status.}

The young adult period is a phase in which changes in marital and employment status typically occur (58). Young adult men and women may go through schooluniversity-workforce transitions and may get married and have children. These changes involve important role transitions (39) and may accordingly change lifestyles, among which PA behavior $(4,17,35)$. The current study shows that marital and employment status were associated with PA in both men and women, that is, 1) women who were divorced were more moderately, but less vigorously, active than those who were living together and/or married; and 2) men and women having no paid work or men working part-time reported more MPA, whereas men working full time reported more VPA than men without paid work. Few prospective studies examined marital and employment status in relation to PA. With regard to marital status, one longitudinal study reported that in young women getting married as well as divorce/separation were associated with decreased time spent in moderate-tovigorous-intensity leisure-time PA (11). In contrast, a study among men and women in their mid-twenties showed that leisure-time PA was not significantly different for those who stayed single, compared with those who became married/cohabiting. Yet in this study, subjects who were married at baseline and separated or divorced at follow-up were excluded from analyses (26). It has to be noted that these studies assessed status changes (e.g., from being single to being married) or marital events (i.e., getting married) as their dependent variable, which is different from how marital status was operationalized in our study. Nevertheless, changes in marital status often come with changes in light and moderate intensity PA levels, that is, house work and care giving activities (1), and mostly for women (19). This supports our finding that marital status was associated with PA in women, but not in men. Employment status on the other hand was associated with MPA in both men and women and may also be an indicator for time spent in house work and care giving duties; that is, those who are not engaged in paid work may have full days of unpaid house and childcare activities $(21,34)$. This could be an explanation for why having no paid work was associated with more MPA in our sample. Interestingly, working part time compared with working fulltime was associated with more MPA in men, but not in women. Dutch men previously reported "more free time for myself” as the most important benefit of working part time compared with working full time (52). It may be that part-time working men spent part of their extra free time in enjoyable moderate intensity (leisure) activities.

The current study also found an association between working full time and time spent in VPA, but only in men. Possibly, full-time working men may choose to engage in shorter duration high-intensity activity sessions (e.g., running, squash, soccer) than their nonworking peers who may have more time to engage in some of the recalled activities (e.g., walking the dog, cycling to visit family/friends, and gardening). Alternatively, full-time working men may use their financial resources more easily for membership of sports or fitness clubs than those who do not have 
Uijtdewilligen, L., Twisk, J.W.R., Chinapaw, M.J.M., Koppes, L.L.J., Mechelen, W. van, Singh, A.S. Longitudinal person-related determinants of physical activity in young adults. Medicine and Science in Sports and Exercise: 2014, 46(3), 529-536

paid work. Full-time working women may be very much limited in their ability to engage in VPA as they more often have to juggle work with family responsibilities.

\section{Physical, psychological, and behavioral factors.}

Men and women with higher aerobic fitness were more moderately and vigorously active. In addition, women who performed better on the physical flexibility test spent more time in both activity categories, whereas men who reported a good general health status spent more time in VPA. Although the positive association between perceived health and PA has been documented before (31), associations between specific aspects of physical fitness and both MPA and VPA have not been well established. Yet, it seems likely that different aspects of physical fitness are important in enabling time spent in either MPA (e.g., brisk walking, walking the dog, gardening, and domestic and household chores) (1), vigorous-intensity activities (e.g., competitive sports, running, swimming/cycling) (1), or both. Our findings showed that aerobic fitness was consistently and significantly associated with both MPA and VPA in men and women. It has to be noted that 1) the association between physical fitness components and PA is likely to be bidirectional (31) (i.e., people who are physically active increase their physical fitness levels, which in turn encourages them to continue to be physically active, further improving their physical fitness) and 2) PA has been recognized as an important determinant of fitness (18). Regarding the association between personality and PA, our results support the evidence that hints toward a positive association between having an outgoing, sociable, lively, and energetic personality and PA participation (47). Accordingly, the review and meta-analysis of Rhodes and Smith (48) showed that individuals scoring high on extraversion and conscientiousness and low on neuroticism were more likely to engage in PA. In line with these results, we found that women feeling less inadequate and more dominant (e.g., taking initiative, being in charge) spent more time in VPA. However, our results also showed that men scoring higher on hostility (e.g., being hot-tempered, impulsive) (38) and lower on dominance spent more time being moderately active. A possible explanation for this finding might be that men with such personality traits are more likely to engage in team sports where hostility translates into competing against the opponent and less dominance in being a good team player. Unfortunately, the methods of our study do not allow us to reveal the underlying mechanisms of these findings.

Research suggests that risk behaviors tend to cluster within individuals $(12,14,24,51)$. Likewise, our results showed that smoking men were less vigorously active than their nonsmoking peers. Regarding alcohol consumption, we found that men consuming above moderate amounts of alcohol (i.e., >=140 g of alcohol per week) were more likely to be moderately active than nonconsumers. This is in line with previous research that already established the strong link between sports and alcohol consumption $(36,41)$ and the connection of alcohol consumption with masculinity (15). Finally, low caloric intake was associated with more VPA among women only. Low caloric intake and more VPA may point toward women trying to lose weight, which is common in a young adult female population (40).

\section{Implications for practice.}

By identifying important determinants of MPA and VPA in both men and women, the current study primarily aimed to offer useful information for intervention development targeting young adults. According to the Intervention Mapping (IM) 
Uijtdewilligen, L., Twisk, J.W.R., Chinapaw, M.J.M., Koppes, L.L.J., Mechelen, W. van, Singh, A.S. Longitudinal person-related determinants of physical activity in young adults. Medicine and Science in Sports and Exercise: 2014, 46(3), 529-536

protocol (7), identifying determinants of behavior should be the first step in developing initiatives that intend behavioral change. Too often, this step is skipped. However, we recognize that our study only captures a small and fairly specific population. We therefore want to highlight the importance of large scale studies assessing the determinants of both MPA and VPA in the future. In that sense, we agree with Bauman et al. (8), who state that factors potentially effecting PA should be included in public health surveillance systems.

\section{Strengths and limitations.}

The findings of the current study are limited by the fact that 1) our data are based on self-reported PA, which is susceptible to recall bias and social desirable answering (46), and 2) the study sample comprised a small select group of people, which limits the generalizability of our results to the Dutch or any other population. With regard to the first limitation, it should be noted that the semistructured interview applied in this study may be more reliable and valid than self-report by questionnaire only. Yet measurement of PA in 2000 was conducted somewhat differently compared with the previous time points, that is, the PA interview was computer supported. The computer-supported measurement may have led to the slightly higher PA levels relative to the earlier measurements and thus to the unusual time trends that were observed in this sample (i.e., higher medians for both MPA and VPA at age 36 compared with earlier ages). It is unlikely that the change in administration of the PA questionnaire resulted in differential bias, but the effect estimates of both the univariable and multivariable models should be interpreted with caution. Another limitation is that the most recent follow-up measurement of the AGAHLS used for the current analyses dates back to the year 2000, and the individual, social, and political environment has undergone major changes since then. It might therefore be that our findings are not fully applicable to young adults living today. Nevertheless, this is one of the few studies investigating determinants of PA in young adulthood using longitudinal data. Our results offer important information for identifying young adults who are at risk of having an inactive lifestyle and insights into determinants to be addressed in PA promoting initiatives.

\section{CONCLUSIONS}

Sociodemographic, physical, psychological, and behavioral factors were associated with PA from age 21 to $36 \mathrm{yr}$ in Dutch young adults. Our findings showed that, among others, people having no paid work spent more time in MPA, while full-time working men spent more time in VPA. Marital status was only associated with PA for women. Higher aerobic fitness and better physical flexibility (women) were positively associated with both MPA and VPA, whereas good self-reported general health status (men) was positively associated with VPA. Men consuming "above moderate” amounts of alcohol, but also nonsmoking men, were more physically active. The identified determinants could be the starting point for intervention development to increase PA (e.g., by increasing young adults physical fitness) or for identifying risk groups (e.g., smokers).

The authors declare no conflict of interest.

The results of the present study do not constitute endorsement by the American College of Sports Medicine. 
Uijtdewilligen, L., Twisk, J.W.R., Chinapaw, M.J.M., Koppes, L.L.J., Mechelen, W. van, Singh, A.S. Longitudinal person-related determinants of physical activity in young adults. Medicine and Science in Sports and Exercise: 2014, 46(3), 529-536

\section{REFERENCES}

1. Ainsworth BE, Haskell WL, Herrmann SD, et al. 2011 Compendium of physical activities: a second update of codes and MET values. Med Sci Sports Exerc. 2011; 43 (8): 1575-81.

2. Ainsworth BE, Haskell WL, Leon AS, et al. Compendium of physical activities: classification of energy costs of human physical activities. Med Sci Sports Exerc. 1993; 25 (1): 71-80.

3. Ainsworth BE, Haskell WL, Whitt MC, et al. Compendium of physical activities: an update of activity codes and MET intensities. Med Sci Sports Exerc. 2000; 32 (Suppl 9): S498S516.

4. Allender S, Hutchinson L, Foster C. Life-change events and participation in physical activity: a systematic review. Health Promot Int. 2008; 23 (2): 160-72.

5. Artinian NT, Fletcher GF, Mozaffarian D, et al. Interventions to promote physical activity and dietary lifestyle changes for cardiovascular risk factor reduction in adults: a scientific statement from the American Heart Association. Circulation. 2010; 122 (4): 406-41. 6. Bakker I, Twisk JW, van Mechelen W, Mensink GB, Kemper HC. Computerization of a dietary history interview in a running cohort; evaluation within the Amsterdam Growth and Health Longitudinal Study. Eur J Clin Nutr. 2003; 57 (3): 394-404. Bibliographic Links

7. Bartholomew L, Parcel G, Kok G, Gottlieb NH, Fernández ME. Planning Health Promotion Programs: An Intervention Mapping Approach. 3rd ed. San Francisco (CA): Jossey-Bass; 2011. p. 768.

8. Bauman AE, Reis RS, Sallis JF, Wells JC, Loos RJ, Martin BW. Correlates of physical activity: why are some people physically active and others not? Lancet. 2012; 380 (9838): 258-71.

9. Bauman AE, Sallis JF, Dzewaltowski DA, Owen N. Toward a better understanding of the influences on physical activity: the role of determinants, correlates, causal variables, mediators, moderators, and confounders. Am J Prev Med. 2002; 23 (Suppl 2): 5-14. 10. Broekhuizen K, Kroeze W, van Poppel MN, Oenema A, Brug J. A systematic review of randomized controlled trials on the effectiveness of computer-tailored physical activity and dietary behavior promotion programs: an update. Ann Behav Med. 2012; 44 (2): 259-86.

11. Brown WJ, Heesch KC, Miller YD. Life events and changing physical activity patterns in women at different life stages. Ann Behav Med. 2009; 37 (3): 294-305.

12. Chiolero A, Wietlisbach V, Ruffieux C, Paccaud F, Cornuz J. Clustering of risk behaviors with cigarette consumption: a population-based survey. Prev Med. 2006; 42 (5): 348-53.

13. Cleland CL, Tully MA, Kee F, Cupples ME. The effectiveness of physical activity interventions in socio-economically disadvantaged communities: a systematic review. Prev Med. 2012; 54 (6): 371-80.

14. Conry MC, Morgan K, Curry $\mathrm{P}$, et al. The clustering of health behaviours in Ireland and their relationship with mental health, self-rated health and quality of life. BMC Public Health. 2011; 11: 692.

15. Dempster S. I drink, therefore I'm man: gender discourses, alcohol and the construction of British undergraduate masculinities. Gender Educ. 2011; 23 (5): 635-53.

16. Dumith SC, Hallal PC, Reis RS, Kohl HW III. Worldwide prevalence of physical inactivity and its association with human development index in 76 countries. Prev Med. 2011; 53 (12): $24-8$.

17. Engberg E, Alen M, Kukkonen-Harjula K, Peltonen JE, Tikkanen HO, Pekkarinen H. Life events and change in leisure time physical activity: a systematic review. Sports Med. 2012; 42 (5): 433-47.

18. Garber CE, Blissmer B, Deschenes MR, et al. American College of Sports Medicine position stand. Quantity and quality of exercise for developing and maintaining cardiorespiratory, musculoskeletal, and neuromotor fitness in apparently healthy adults: guidance for prescribing exercise. Med Sci Sports Exerc. 2011; 43 (7): 1334-59.

19. García-Mainar I, Molina JA, Montuenga VM. Gender differences in childcare: time allocation in five European countries. Fem Econ. 2011; 17 (1): 119-50.

20. Gough HG. Manual for the CPI, California Psychological Inventory. Palo Alto: Consulting Psychological Inventory; 1964. p. 60.

21. Gough M, Killewald A. Unemployment in families: the case of housework. J Marriage Fam. 2011; 73 (5): 1085-100. 
Uijtdewilligen, L., Twisk, J.W.R., Chinapaw, M.J.M., Koppes, L.L.J., Mechelen, W. van, Singh, A.S. Longitudinal person-related determinants of physical activity in young adults. Medicine and Science in Sports and Exercise: 2014, 46(3), 529-536

22. Hallal PC, Andersen LB, Bull FC, Guthold R, Haskell W, Ekelund U. Global physical activity levels: surveillance progress, pitfalls, and prospects. Lancet. 2012; 380 (9838): 247-57.

23. Health Council of the Netherlands. Guidelines for a Healthy Diet. The Hague: Health Council of the Netherlands; 2006. p. 110 Available from: Health Council of the Netherlands, The Hague.

24. Heroux M, Janssen I, Lee DC, Sui X, Hebert JR, Blair SN. Clustering of unhealthy behaviors in the Aerobics Center Longitudinal Study. Prev Sci. 2012; 13 (2): 183-95.

25. Hildebrandt VH, Bernaards CM, Chorus A, Hofstetter H. Bewegen in Nederland 20002011 [Physical activity in the Netherlands 2000-2011]. Hildebrandt VH, Bernaards CM, Stubbe JH, editors. Trendrapport Bewegen en Gezondheid 2010/2011 [Trend Report on Physical Activity and Health 2010/2011]. Leiden: De Bink; 2013. pp. 9-50.

26. Hull EE, Rofey DL, Robertson RJ, Nagle EF, Otto AD, Aaron DJ. Influence of marriage and parenthood on physical activity: a 2-year prospective analysis. J Phys Act Health. 2010; 7 (5): 577-83.

27. Hutchinson AD, Wilson C. Improving nutrition and physical activity in the workplace: a meta-analysis of intervention studies. Health Promot Int. 2012; 27 (2): 238-49.

28. Jansen ME, Sikkel D. Verkorte versie van de voegschaal [Shortened version of the VOEG scale]. Gedrag Samenl. 1981; 2: 78-82.

29. Kahn EB, Ramsey LT, Brownson RC, et al. The effectiveness of interventions to increase physical activity. A systematic review. Am J Prev Med. 2002; 22 (Suppl 4): 73-107.

30. Kemper HCG, Bakker I, Twisk JWR, van Mechelen W. Validation of a physical activity questionnaire to measure the effect of mechanical strain on bone mass. Bone. 2002; 30 (5): 799-804.

31. Kemper HCG, Koppes LLJ. Linking physical activity and aerobic fitness: are we active because we are fit, or are we fit because we are active? Pediatr Exerc Sci. 2006; 18 (2): 173-81.

32. Kemper HCG, van Mechelen W. Methods and measurements used in the longitudinal study. Kemper HCG, editor. The Amsterdam Growth Study. A Longitudinal Analysis of Health, Fitness, and Lifestyle. Champaign: Human Kinetics; 1995. pp. 28-49.

33. Koppes LL, Twisk JW, Snel J, Kemper HC. Concurrent validity of alcohol consumption measurement in a 'healthy' population; quantity-frequency questionnaire $v$. dietary history interview. Br J Nutr. 2002; 88 (4): 427-34.

34. Krueger AB, Mueller Al. The lot of the unemployed: a time use perspective. J Eur Econ Assoc. 2012; 10 (4): 765-94.

35. Larouche R, Laurencelle L, Shephard RJ, Trudeau F. Life transitions in the waning of physical activity from childhood to adult life in the Trois-Rivieres study. J Phys Act Health. 2012; 9 (4): 516-24.

36. Lisha NE, Sussman S. Relationship of high school and college sports participation with alcohol, tobacco, and illicit drug use: a review. Addict Behav. 2010; 35 (5): 399-407.

37. Loef $\mathrm{M}$, Walach $\mathrm{H}$. The combined effects of healthy lifestyle behaviors on all cause mortality: a systematic review and meta-analysis. Prev Med. 2012; 55 (3): 163-70.

38. Luteijn F, Starren J, van Dijk H. Herziene Handleiding NPV [Revised Manual of the Dutch Personality Inventory]. Lisse: Swets \& Zeitlinger; 1985. p. 31.

39. Maggs JL, Jager J, Patrick ME, Schulenberg J. Social role patterning in early adulthood in the USA: adolescent predictors and concurrent wellbeing across four distinct configurations. Longit Life Course Stud. 2012; 3 (2): 190-210.

40. Neumark-Sztainer D, Sherwood NE, French SA, Jeffery RW. Weight control behaviors among adult men and women: cause for concern? Obes Res. 1999; 7 (2): 179-88.

41. O'Farrell AM, Allwright SP, Kenny SC, Roddy G, Eldin N. Alcohol use among amateur sportsmen in Ireland. BMC Res Notes. 2010; 3: 313.

42. Orrow G, Kinmonth AL, Sanderson S, Sutton S. Republished research: effectiveness of physical activity promotion based in primary care: systematic review and meta analysis of randomised controlled trials. Br J Sports Med. 2013; 47 (1): 27.

43. Penedo FJ, Dahn JR. Exercise and well-being: a review of mental and physical health benefits associated with physical activity. Curr Opin Psychiatry. 2005; 18 (2): 189-93.

44. Post GB, Kemper HCG. Cross-check dietary history and 24-hour dietary recall. Voeding. 1980; 41: 123-29. 
Uijtdewilligen, L., Twisk, J.W.R., Chinapaw, M.J.M., Koppes, L.L.J., Mechelen, W. van, Singh, A.S. Longitudinal person-related determinants of physical activity in young adults. Medicine and Science in Sports and Exercise: 2014, 46(3), 529-536

45. Post GB, Kemper HCG. Procedures and subjects used in the Longitudinal Study. In: Kemper HCG, editor. The Amsterdam Growth Study. A Longitudinal Analysis of Health, Fitness, and Lifestyle. Champaign: Human Kinetics; 1995. pp. 17-27.

46. Prince SA, Adamo KB, Hamel ME, Hardt J, Gorber SC, Tremblay M. A comparison of direct versus self-report measures for assessing physical activity in adults: a systematic review. Int J Behav Nutr Phys Act. 2008; 5: 56.

47. Rhodes RE. The built-in environment: the role of personality and physical activity. Exerc Sport Sci Rev. 2006; 34 (2): 83-8.

48. Rhodes RE, Smith NE. Personality correlates of physical activity: a review and metaanalysis. Br J Sports Med. 2006; 40 (12): 958-65.

49. Trost SG, Owen N, Bauman AE, Sallis JF, Brown W. Correlates of adults' participation in physical activity: review and update. Med Sci Sports Exerc. 2002; 34 (12): 1996-2001.

50. Twisk JWR, Kemper HCG. Design of the Amsterdam Growth Study. In: Kemper HCG, editor. The Amsterdam Growth Study. A Longitudinal Analysis of Health, Fitness, and Lifestyle. Champaign: Human Kinetics; 1995. pp. 6-16.

51. Twisk JW, Kemper HC, van Mechelen W, Post GB. Clustering of risk factors for coronary heart disease. the longitudinal relationship with lifestyle. Ann Epidemiol. 2001; 11 (3): 15765. Bibliographic Links

52. van der Horst T, de Jongh M. (Voor)oordelen Over Parttimers. Echte Mannen Werken Fullime [(Pre)judgements about Part Timers. Real Men Work Full Time]. Amsterdam: TNS NIPO; 2008. p. 75 Available from: TNS NIPO, Amsterdam.

53. Verschuur R. Daily physical activity and health. Longitudinal Changes During the Teenage Period [dissertation]. Haarlem (the Netherlands): University of Amsterdam; 1987. p. 229.

54. Vingerhoets AJJM, Flohr PJM. Type A behavior and self-reports of coping preferences. Br J Med Psych. 1984; 57 (1): 15-21.

55. Weiner JS, Lourie JA. Human Biology: A Guide to Field Methods. Oxford: Blackwell; 1968. p. 621.

56. Welsman JR, Armstrong N, Nevill AM, Winter EM, Kirby BJ. Scaling peak $\mathrm{V} \cdot \mathrm{O}_{2}$ for differences in body size. Med Sci Sports Exerc. 1996; 28 (2): 259-65.

57. World Health Organisation. Global Health Risks. Mortality and Burden of Disease Attributable to Selected Major Risks. Geneva (Switzerland): World Health Organization; 2009. p. 62. Available from: WHO, Geneva.

58. Wrzus C, Hanel M, Wagner J, Neyer FJ. Social network changes and life events across the life span: a meta-analysis. Psychol Bull. 2013; 139 (1): 53-80.

\section{TABLES}


TABLE 1. Self-reported time spent in moderate and vigorous PA at ages $21,27,32$, and $36 \mathrm{yr}$.

\begin{tabular}{|c|c|c|c|c|c|c|c|c|c|c|c|c|}
\hline & \multicolumn{12}{|c|}{ Average Age at Follow-up Measurement (yr) } \\
\hline & \multicolumn{3}{|c|}{21} & \multicolumn{3}{|c|}{27} & \multicolumn{3}{|c|}{$\begin{array}{r}32 \\
\end{array}$} & \multicolumn{3}{|c|}{$36^{a}$} \\
\hline & $N$ & Median & $\begin{array}{c}\text { Interquartile } \\
\text { Range }\end{array}$ & $N$ & Median & $\begin{array}{c}\text { Interquartile } \\
\text { Range }\end{array}$ & $N$ & Median & $\begin{array}{c}\text { Interquartile } \\
\text { Range } \\
\end{array}$ & $N$ & Median & $\begin{array}{c}\text { Interquartile } \\
\text { Range }\end{array}$ \\
\hline \multicolumn{13}{|c|}{ Moderate PA (min $\left.\cdot \mathrm{wk}^{-1}\right)$} \\
\hline$\sigma^{\pi}$ & 93 & 380 & 284 & 84 & 197 & 380 & 206 & 266 & 313 & 178 & 449 & 623 \\
\hline 우 & 107 & 385 & 415 & 98 & 331 & 346 & 232 & 327 & 333 & 199 & 605 & 566 \\
\hline \multicolumn{13}{|c|}{ Vigorous PA (min $\mathrm{wk}^{-1}$ ) } \\
\hline
\end{tabular}

auring the 2000 follow-up, the PA interview was computer supported, which may explain the higher levels in moderate PA for both men and women at age $36 \mathrm{yr}$ (6).

$N$, number of participants; PA, physical activity.

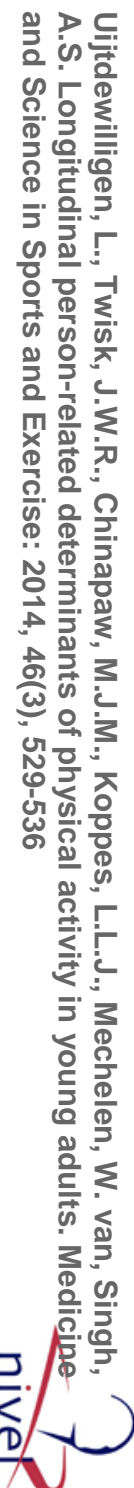


Uijtdewilligen, L., Twisk, J.W.R., Chinapaw, M.J.M., Koppes, L.L.J., Mechelen, W. van, Singh, A.S. Longitudinal person-related determinants of physical activity in young adults. Medicine 7 and Science in Sports and Exercise: 2014, 46(3), 529-536

TABLE 2. Characteristics of AGAHLS participants at different time points.

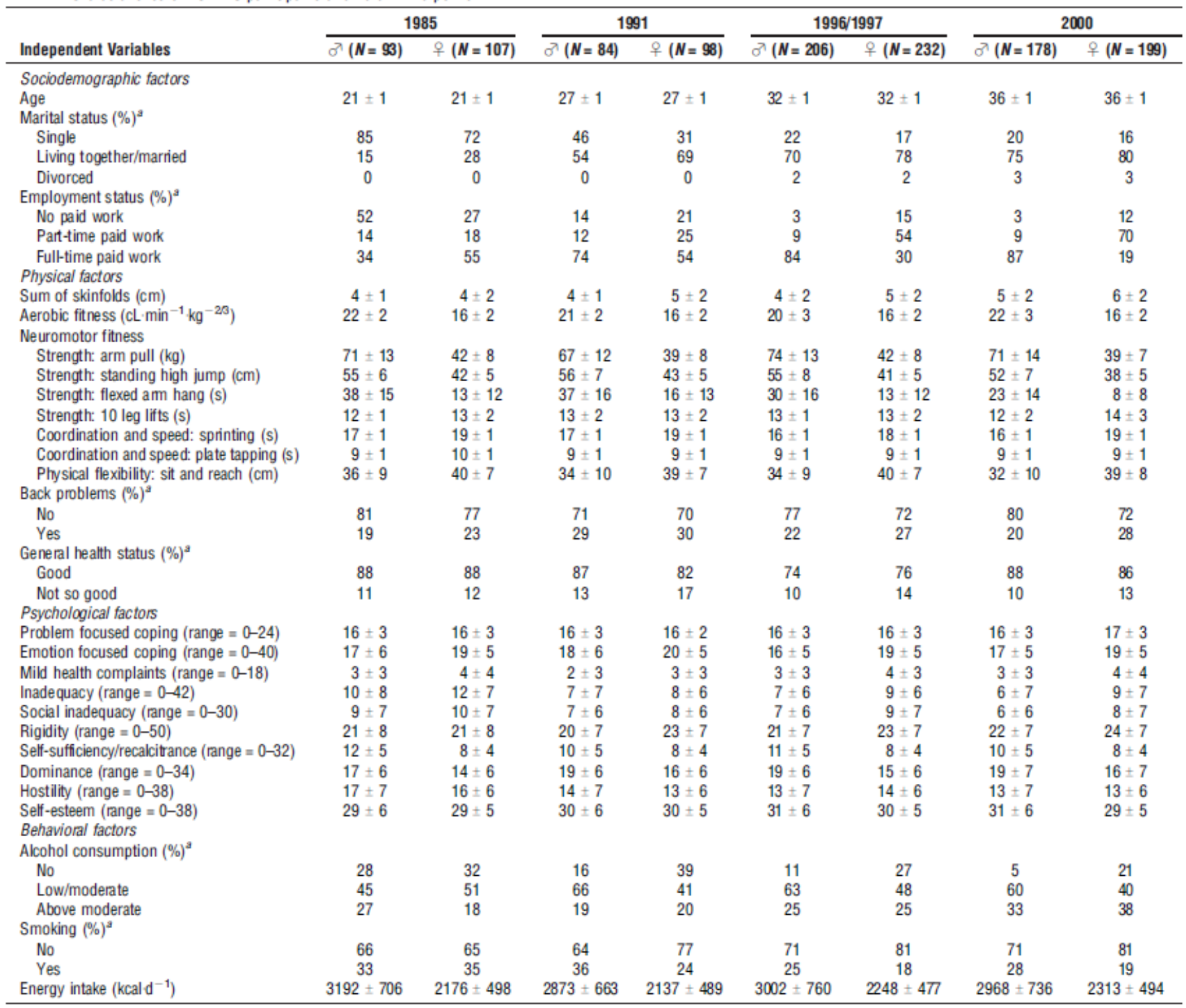

Data are presented as mean \pm SD unless otherwise indicated.

${ }^{2}$ Because of rounding and missing data, not all percentages of the categorical independent variables add up to $100 \%$. 
Uijtdewilligen, L., Twisk, J.W.R., Chinapaw, M.J.M., Koppes, L.L.J., Mechelen, W. van, Singh, A.S. Longitudinal person-related determinants of physical activity in young adults. Medicine and Science in Sports and Exercise: 2014, 46(3), 529-536

TABLE 3. Results of multivariable GEE analyses presenting significant associations between person-related characteristics and moderate PA for men and women separately (adjusted for age at each time point).

\begin{tabular}{|c|c|c|c|c|}
\hline \multirow[b]{3}{*}{ Independent Factor (Reference Category) } & \multicolumn{4}{|c|}{ MPA } \\
\hline & \multicolumn{2}{|c|}{$\sigma^{7}$} & \multicolumn{2}{|c|}{ 우 } \\
\hline & Effect $^{a}$ & $95 \% \mathrm{CI}$ & Effect $^{2}$ & $95 \% \mathrm{Cl}$ \\
\hline \multicolumn{5}{|l|}{ Sociodemographic factors } \\
\hline \multicolumn{5}{|l|}{ Marital status (living together/married) ${ }^{b}$} \\
\hline Single & - & - & 1.05 & $0.97-1.13$ \\
\hline Divorced & - & - & $1.25^{*}$ & $1.03-1.50$ \\
\hline \multicolumn{5}{|l|}{ Employment status (full-time paid work) } \\
\hline No paid work & $1.27^{\star \star}$ & $1.08-1.49$ & $1.09^{*}$ & $1.01-1.19$ \\
\hline Part-time paid work & $1.22^{\star \star}$ & $1.06-1.42$ & 1.02 & $0.95-1.11$ \\
\hline \multicolumn{5}{|l|}{ Physical factors } \\
\hline Aerobic fitness & $1.02^{\star *}$ & $1.01-1.04$ & $1.02^{\star \star}$ & $1.01-1.04$ \\
\hline MOPER flexibility & - & - & $1.05^{\star \star}$ & $1.02-1.09$ \\
\hline \multicolumn{5}{|l|}{ Psychological factors ${ }^{c}$} \\
\hline Dominance & $0.96^{*}$ & $0.93-1.00$ & - & - \\
\hline $\begin{array}{l}\text { Hostility } \\
\text { Hon }\end{array}$ & $1.08^{\star \star \star}$ & $1.04-1.12$ & - & - \\
\hline \multicolumn{5}{|l|}{ Behavioral factors } \\
\hline \multicolumn{5}{|l|}{ Alcohol consumption (no) $)^{d}$} \\
\hline Low/moderate & 1.15 & $0.98-1.36$ & - & - \\
\hline Above moderate & $1.21^{*}$ & $1.01-1.44$ & - & - \\
\hline
\end{tabular}

${ }^{a}$ For continuous variables, a value higher than 1 represents a higher PA level for each additional step on the determinant scale. For categorical variables, a value higher than 1 represents higher PA levels compared with the reference group.

'Marital status with reference category 'single' showed no significant results. Marital status with reference category 'living together/married' did show significant differences between groups of women and was therefore retained as variable in the model.

"For all psychological factors, the outcome signifies five steps on the scale.

${ }^{d}$ Alcohol consumption with the reference category 'low/moderate' showed no significant results. Alcohol consumption with the reference category 'no' did show significant differences between groups of men and was therefore retained as variable in the model.

${ }^{\star} P<0.05,{ }^{\star \star} P<0.01,{ }^{\star \star \star}{ }^{*} P<0.001$.

$\mathrm{Cl}$, confidence interval.

TABLE 4. Results of multivariable GEE analyses presenting significant associations between person-related characteristics and vigorous PA for men and women separately (adjusted for age at each time point).

\begin{tabular}{|c|c|c|c|c|}
\hline \multirow[b]{3}{*}{ Independent Factor (Reference Category) } & \multicolumn{4}{|c|}{ VPA } \\
\hline & \multicolumn{2}{|c|}{$\sigma^{7}$} & \multicolumn{2}{|c|}{ 우 } \\
\hline & Effect $^{2}$ & $95 \% \mathrm{Cl}$ & Effect $^{2}$ & $95 \% \mathrm{Cl}$ \\
\hline \multicolumn{5}{|l|}{ Sociodemographic factors } \\
\hline Single & - & - & 0.91 & $0.82-1.02$ \\
\hline Divorced & - & - & $0.78^{\star \star}$ & $0.66-0.92$ \\
\hline \multicolumn{5}{|l|}{ Employment status (full-time paid work) } \\
\hline No paid work & $0.84^{\star}$ & $0.70-1.00$ & - & - \\
\hline Aerobic fitness & $1.05^{\star \star \star}$ & $1.03-1.06$ & $1.06^{\star \star \star}$ & $1.04-1.09$ \\
\hline MOPER flexibility & - & - & $1.05^{\star}$ & $1.01-1.09$ \\
\hline Not so good general health & $0.86^{\star}$ & $0.74-0.99$ & - & - \\
\hline \multicolumn{5}{|l|}{ Psychological factors ${ }^{c}$} \\
\hline Inadequacy & - & - & $0.96^{*}$ & $0.92-0.99$ \\
\hline Dominance & - & - & $1.09^{\star \star \star}$ & $1.06-1.13$ \\
\hline \multicolumn{5}{|l|}{ Behavioral factors } \\
\hline
\end{tabular}

For continuous variables, a value higher than 1 represents a higher PA level for each additional step on the determinant scale. For categorical variables, a value higher than 1 represents higher PA levels compared with the reference group.

'Marital status with reference category 'single' showed no significant results. Marital status with reference category 'living together/married' did show significant differences between groups of women and was therefore retained as variable in the model.

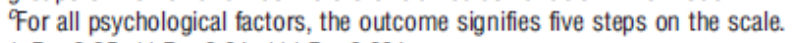

${ }^{\star} P<0.05,{ }^{\star \star} P<0.01,{ }^{\star \star \star}{ }^{\circ} P<0.001$.

$\mathrm{Cl}$, confidence interval. 